\title{
Bliv Data Steward - en ny uddannelse
}

\section{Data Stewardship og rollen som data steward er stadig under modning i Danmark og der er endnu ingen klar definition af rollen. En ny rapport identificerer imidlertid et bredt behov og en efterspørgsel på uddannelse og kvalifikationer inden for området data stewardship i Danmark, der går på tværs af den offentlige og private sektor. Resultaterne peger både på udfordringer og muligheder for at få udbredt kendskabet og adresseret behovet for Data Stewards som kompetence og arbejdskraft og rapporten kan betragtes som et første input til de uddannelsesinstitutioner, der overvejer at udbyde data stewardship som et kommende uddannelsesområde i Danmark.}

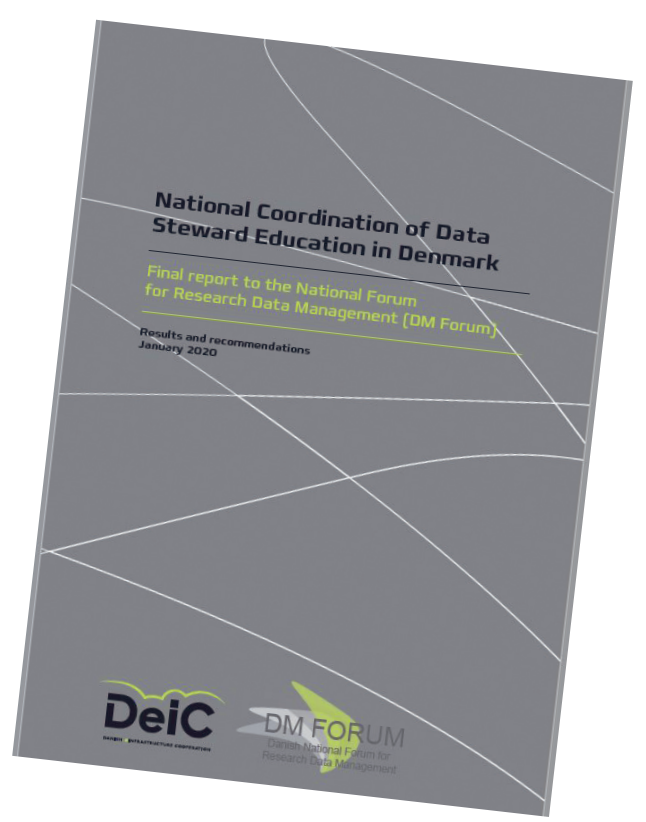

\section{Om Data Steward projektet}

Projektet National koordinering af Data Stewardship uddannelse i Danmark, der er støttet af nu nedlagte DEFF og DM Forum (DeiC), har haft til formål bredt at afdække det danske samfunds behov for data stewardship med henblik på at undersøge grundlaget for etableringen af en ny uddannelsesmulighed som data steward. Aftagerne til projektets leverancer er overvejende danske universiteter, professionshøjskoler, den offentlige sektor (kommuner, statslige institutioner), samt dansk industri og erhvervsliv, men også det internationale miljø og de europæiske organisationer, der på lignende vis arbejder med data stewardship i relation til uddannelse, træning og opbygning af kvalifikationer og kompetencer på området.

Ud over projektets hovedrapport (Wildgaard et al. 2020), der bl.a. bygger på et systematisk review af danske og udenlandske data stewardship programmer og certificeringer (Wildgaard 2020) og projektets dokumentation i form af indsamlede data (Vlachos et al. 2020), blev der i oktober sidste år afholdt en stor konference: Data Steward Education: Coordination or competition? på Københavns Universitet med flere end 100 deltagere. Formålet var at samle de identificerede interessenter fra potentielle udbydere og aftager af DS til videre kvalificering af det spirende fokusområde for dansk industri og danske uddannelsesinstitutioner. Omkring projektet har der desuden været stor international bevågenhed fra både forskningsinfrastrukturer, EU-projekter samt universiteter, politiske organisationer og dansk erhvervsliv, hvor projektet har formidlet flere af sine resultater (se yderligere kommunikation).

Projektets resultater peger klart på behovet for etablering af en ny data steward uddannelse i Danmark samtidigt med en stærk opfordring til netværksopbygning i Danmark, der 
kan samle og koordinere et spredt og diffust område, der vil være i vækst i de kommende mange år i Danmark på tværs af sektorer og som kan sikre erfaringsudveksling og give mulighed for at bidrage med danske erfaringer til andre internationale netværk, der begynder at etablere sig.

Hovedrapporten "National Coordination of Data Steward Education in Denmark" præsenterer et forslag til fremtidige danske universitetsuddannelser i data stewardship. Forslaget bygger på analyser af nuværende uddannelser eller certificeringer inden for data stewardship og en evaluering af behovet og forventninger til rollen som en data steward (DS) på tværs af de private og offentlige sektorer. Metoder til analyser i rapporten inkluderede en kombination af kvantitative og kvalitative metoder såsom systematisk review, text mining, spørgeskemaer, korrelationsanalyser og interviews.

\section{Data Stew...hvad?}

Resultaterne viser at DS leverer et væld af tjenester i forhold til, hvor de er ansatte henne og den kontekst de praktiserer data stewardship i. Primært fungerer DS som en bro mellem organisationen, den tekniske infrastruktur og slutbrugeren eller kunden. Vi identificerede fire fælles roller, der går på tværs af alle sektorer. Disse er data stewarden (DS) som: administrator, analytiker, udvikler og forandringsagent.
Særligt for DS der arbejder i et servicemiljø inden for IT og/eller biblioteker er rollen som:

- administrator forbundet med en der lærer hurtigt og som udfordres af at forstå processer og procedurer og som er god til at risikovurdere IT-løsninger.

- udvikler en medarbejder der forstår at optimere processer og systemer og som arbejder i et team med compliance -og datasikkerhedseksperter om at etablere best practices.

- etik ekspert, der har styr på GDPR, god data praksis ift. integritet og etik.

Vi anbefaler en uddannelsesmodel i Data Stewardship, der understøtter erfaringsmæssig læring og praktikpladser og som giver fleksibilitet til at omfatte de aktiviteter og det engagement, som praktikpladser indebærer. Ligeledes er det vigtigt at sikre en balance mellem de "hårde" tekniske færdigheder som programmering og work-flow optimering og de "bløde" færdigheder, som findes typisk i undervisning, kommunikation, netværksskabelse og projektledelse såvel som disciplinær viden og god data management praksis (etik, politik og ansvarlighed)

I rapporten anbefaler vi følgende to uddannelsesmodeller.
- en 2-årig kandidat i data stewardship med moduler der er tilgængelige gennem Åbent Universitet og dermed støtter modne studerende med en professionel baggrund

- et 1-årig masterprogram i data stewardship (BA +1.) under forudsætning af at det er åbent for studerende med mindst en bachelor. Således kan programmet også være åbent for masterstuderende, ph.d.er og gennem Åbent Universitet for modne studerende. På de nævnte betingelser har den 1-årige uddannelse potentialet til at give et dynamisk læringsmiljø og relevant opkvalificering, der hurtigt kan levere DS til det sultne jobmarked.

Desuden peger rapporten på tre modeller for en prækvalificering af DS uddannelse der kan sikre spektret fra studerende over aktive forskere til efter - og videreuddannelse.

\section{Data Stewardship - koordinering eller konkurrence?}

I DeiC rapporten besvares spørgsmålet om en DS-uddannelse bør udvikles i tæt national koordinering mellem universiteter og industri, eller om sund konkurrence mellem disse parter vil resultere i forskellige uddannelsesprogrammer, der appellerer til forskellige publikum. Der er adskillige internationale indsatser for koordinering af Data Stewardship på tværs af akademiske

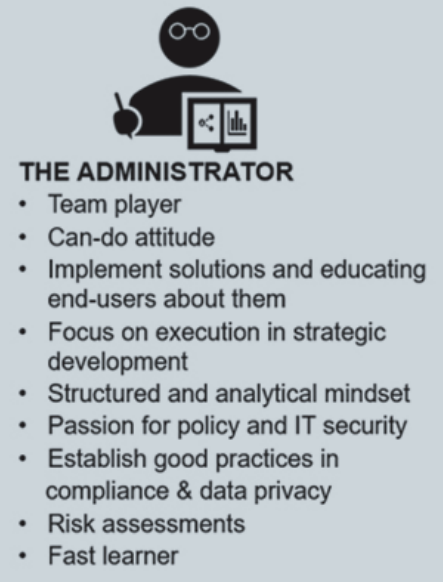

The 4 roles of a Data Steward

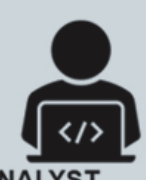

THE ANALYST

- Programmer

- Statistical \& data analyst

- Fast learner and innovative on building custom software and databases

- Ensure data quality

- Enthusiasm in cloud solutions

- Seek challenges, have positive attitude towards reporting

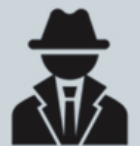

THE AGENT OF CHANGE

THE DEVELOPER

- Process optimization via good project management

- FAIR principles advisor

- Data planner

- Focus on collaboration and knowledge sharing to raise business intelligence

- Innovative

- Develop procedures \& guidelines
- Client \& customer oriented

- Mediate processes \& operations

- Passionate to implement solutions via project $\&$ change management

- User empathy

- Focus on execution of policy and strategy awareness

- Agile mindset

- Enthusiastic 
interessenter, bl.a. GoFAIR, FAIRsFAIR, og EOSC. Men en EUA fokusgruppe, nedsat i november 2019, der har til formål at udvikle uddannelsesmaterialer og curricula i datahåndtering og data stewardship konkluderede, at der er en mangel på information om samtlige indsatser, initiativer og træningsmateriale på nationalt, europæisk og internationalt plan. Derfor understreger DeiC rapporten vigtigheden af, at koordinering af DS-uddannelse i Danmark er geografisk tilpasset til at imødekomme efterspørgslen til DS i det lokale miljø og på det nationale plan samt til både generiske og disciplin-specifikke kompetencerammer for data stewardship. Rapporten anbefaler en fælles national tilgang til en universitetsuddannelse i data stewardship og engagement i nationale og europæiske initiativer på en koordineret møde for at sikre jobmobilitet og den frie bevægelighed for arbejdskraft i overensstemmelse med Bologna-processen og det europæiske HE-område.

\section{Uddannelsesmuligheder i Data Stewardship}

I rapporten diskuterer vi, hvordan data stewardship uddannelser i erhvervslivet er velintegreret i et bredt udvalg af virksomheder lige fra lifestyle og design til finans og forskning, fx Estée Lauder, IKEA, SKAT og Novo Nordisk. Data stewards bliver uddannet "on the job” og kan f.eks. være integreret i et karriereforløb og mesterlærling-programmer eller inden for specifik stewardship-software og -platforme, fx e-læringsmoduler fra IBM eller Dell i korte "in-house" kompetenceudviklingsforløb. Hvorimod inden for akademia, er data stewardship uddannelser kun i sine vorden og træningsforløb primært målrettet de våde videnskaber.

Hvis du på nuværende tidspunkt vil efteruddanne dig som DS i Danmark, har du begrænsede muligheder. Der er langt mellem sammensætte kompetencegivende uddannelsesmuligheder, der udmønter sig i en akademisk grad eller anerkendt kvalificering hos ens arbejdsgivere. Du kan på Syddansk Universitet tage en kandidatgrad i Data Science, hvor uddannelsens sigte er de praktiske færdigheder, der er nødvendige at tilegne sig for professionel databehandling og bl.a. data stewardship i danske virksomheder, styrelser eller andre forskningstunge institutioner. Ligeledes kan du på København Universitets Fakultet for Samfundsvidenskab tage en kandidat i social datavidenskab, der handler om data i relation til menneskets adfærd, handlinger, vaner og beslutninger, herunder data governance, data etik, datasikkerhed og databehandling En del kandidatuddannelser kan, i forskellige omfang, tages på deltid, hvor du efter reglerne for deltidsundervisning og din adgangsgivende faglighed, kan følge et enkelt fag eller modul mod deltagerbetaling og dermed strikke din egen uddannelsesprofil sammen.
Som alternativ, kan du deltage i en 5-dages teknisk introduktion til FAIR Data Stewardship, der tilbydes af NeIC og Phortos Consultants og efterhånden ser ud til at være en tilbagevendende årlig begivenhed. Sommerskoler er også en mulighed, for eksampel Social Data Science og Managing and Analysing Data in Social Science som begge skubber grænserne for, hvordan man arbejder med data på en ansvarlig måde.

Der er bred enighed $\mathrm{i}$ at en uddannelse i data stewardship burde tilbydes som videreuddannelse for at sikre både vedligeholdelse og opdatering af en data stewards viden, færdigheder og kompetencer. Projekter og konsortier der rådgiver højere uddannelsesanstalter, fx FAIRsFAIR, EUA, EOSC og Science Europe, drøfter alle pt. input til mulige Data Stewardship curricula, hvori industri identificeres som vigtig samarbejdspartnere . Ligeledes tilbyder europæiske faglige råd og organisationer, fx GOFAIR, CODATA og RDA korte træningsforløb. Fokus ser ud til at være data stewards, der kan FAIRify data og tilbyde projektbistand i de våde videnskaber.

I Danmark arbejder vi med at lægge et solidt fundament for professionalisering af data stewardship i mange arbejdskontekster, herunder kompetencer i data stewardship terminologi, integration af data stewardship på tværs af en organisation, jobprofiler,

\section{The 3 models for Data Stewardship Education}

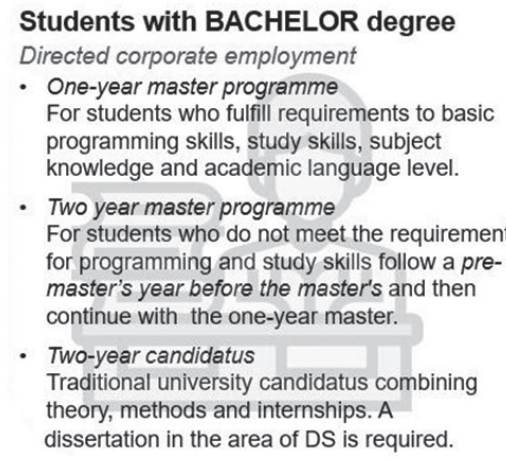

\section{Students with a PH.D. or equivalent} Directed corporate or academic employment For PhDs from any field at university faculties or part of research teams in industry. Educational programmes are a collaborative endeavor between faculties, library or knowledge centers, Centers for Information Security, Data Steward Community, Research coordinators, Project PI's, System Developers, Communication and Teaching teams, the Graduate School (for PhD training) \& Human Research Ethics Committees.

- Requirements: Short courses, workshops, mentorships, online modules, summer school programmes \& MOOCs, that immerse the student in the DS Community.
VET-students (Vocational Education \& Training)

Directed corporate or academic employment

Flexible master programme

- For students who have professional experience and wish to improve their DS skills but keep working full-time, or already have a master's degree in any field.

- The programme is a part-time vocational education with a prescribed period of study, that the student individually plans, and a total of 60 ECTS-points.

- The student combines elements from established programmes, thus it is a requirement that DS courses, such as the one year master and two year candidatus, are available through the Open University. 
uddannelse, karrierespor, netværk og videnudveksling og certificering. På baggrund af DeiC rapporten ser vi et behov for fleksible (efter)uddannelser i data stewardship, der vil klæde både nye dimittender og erfarne medarbejdere på med de nødvendige forudsætninger for at udfylde data steward stillinger på universiteter men også i offentlige og private virksomheder. Derfor er en arbejdsgruppe på Københavns Universitet i gang med at udvikle en ny 1-årig overbygningsuddannelse i data stewardship. Prækvalifikationsarbejdet er en tværfaglig opgave, som løftes af samtlige fakulteter på KU og universitetsbiblioteket med inddragelse af interessenter fra erhvervslivet. Tilgangen følger anbefalingerne om professionalisering af data stewardship fra bl.a. LCRDM rapporten "Data Stewardship on the map", Porto Open Science FAIR "Time to Professionalise Data Stewardship", EDISON-projektet og vores egen DeiC rapport. Ambitionen er at skabe en ny form for tværinstitutionel uddannelse, der tiltaler netop arbejdsmarkedets diverse og unikke måder at arbejde med data på. Rationalet bag uddannelsen er at et stærkt samarbejde mellem akademia og erhvervslivet, der skal sikre en uddannelse, hvis relevans anerkendes blandt aftagere og interessenter i samfundet, herunder potentielle arbejdsgivere. Hvis Data Steward-uddannelsen godkendes, vil den have optag fra september 2021 for ansøgere med minimum en bestået bachelor fra

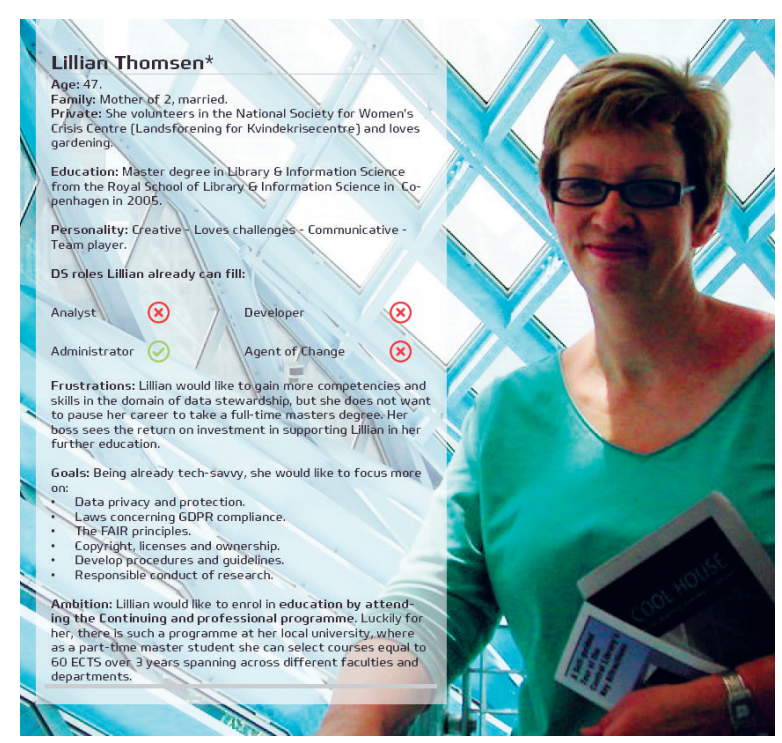

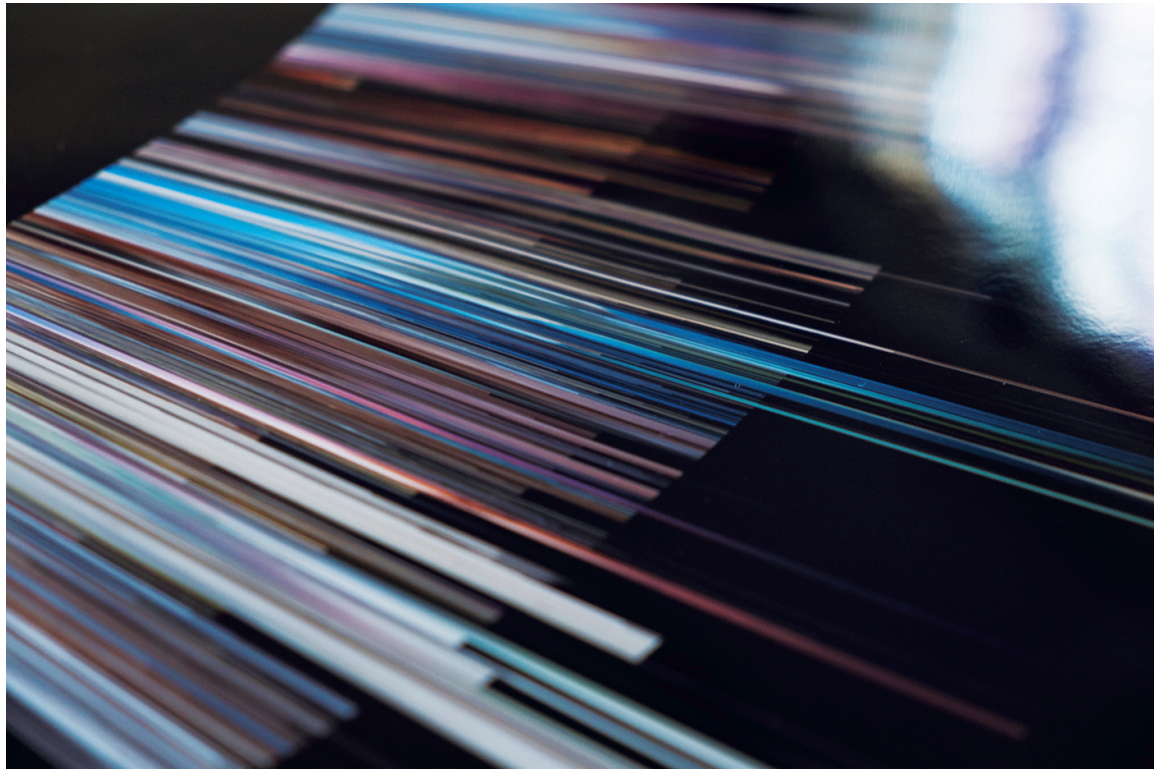

et universitet. Ligeledes påtænkes der også at udvikle en overbygningsuddannelse i Data Stewardship på Syddansk Universitet.

\section{Biblioteket og Data Stewardship}

Data Steward-støtte på biblioteket, centralt og lokalt, er bestemt nødvendigt på lang sigt. Open Science og eScience stiller krav til systemer, der identificerer, indsamler, genbruger, dokumenterer og opbevarer data. Disse systemer indebærer krav til robuste metadataskemaer og ontologier, der beskriver relationerne mellem data og elementer i et workflow samt dokumentation af anvendte processer og modeller. Ovenstående systemer og workflows kan biblioteket træde ind $\mathrm{i}$, i rollen som DS. Men bibliotekets viden, kunnen og ressourcer vil til tider blive presset. At flytte biblioteket fra rollen som "manager" af digitale objekter, ontologier og metadata til en rolle, hvor biblioteket dokumenterer datamodeller, ontologier og workflows samt leverer services, der vil hjælpe brugere og kunder med at finde, validere, kvalitetssikre og bruge relevante datakilder, er både en kulturel ændring og en kompetenceændring for bibliotekets ansatte. Denne ændring har en simpel løsning: investér i og vedligehold bibliotekarens DS viden, færdigheder og kompetencer. Men så simpelt er det ikke! For det første er der en manglende konsensus om hvilke ansvar og kompetencer samt viden og værdi en DS bør have, hvilket fører til forvirring. For det andet mangler vi sammenhængende og dedikerede DS træningsprogrammer, både internationalt og nationalt. $\mathrm{Og}$ for det tredje er sparsomme ressourcer for DS-aktiviteter i mange organisationer begrænset af ansættelse af og karrierespor i DS. Hvordan kan biblioteket helt grundlæggende forny sig hvis ingen efter- eller videreuddannelse målrettes opkvalificering af bibliotekarer? Og som konsekvens heraf, hvordan kan biblioteket således nogenlunde hurtigt levere et katalog af DS services, der fx kræves i nationale FAIR data strategier og universiteternes egne ambitioner med lokale research data management politikker og services?

Hver eneste DS service stiller forskellige krav og forventninger til DS kompetencer. Der er ingen bibliotekarer eller intet universitet, bibliotek eller virksomhed der kan løfte DS agendaen alene. Samarbejde er nøglen via tværinstitutionelle projekter, netværk og centre, der kan give sammenhængende muligheder for uddannelse, vidensde- 
ling, opkvalificering og deltagelse i udvikling af data praksisser og DS service modeller. I DeiC-rapporten efterspørger vi en fælles national tilgang til universitetsuddannelse i Data Stewardship, hvor engagement i nationale, europæiske og internationale initiativer sker på en koordineret måde for at sikre både en uddannelse, der er tilpasset politik, initiativer og retninger inden for Data Stewardship, og jobmobilitet for data stewards uddannet i Danmark. Sådan en koordinering kunne indebære:

- F \& U-sektorer, herunder fælles netværk dedikeret til at arbejde med overførbare færdigheder og digitale kompetencer.

- Styring af koordinationen med Data Stewardship i Danmark bør pege på uddannelsesudvalg som Det rådgivende udvalg for vurdering af udbud af videregående uddannelser (RUVU)

- Uddannelsesudvalg ved Danmarks Universiteter forventes at have ansvaret for at koordinere fremtidige Data Steward uddannelsesniveauer (Bachelor, Master, Candidatus samt efter -og erhvervsuddannelse).
- en koordinering af DS-uddannelse i Danmark, der er geografisk tilpasset til at imødekomme efterspørgslen til DS i det lokale miljø og på det nationale plan og til både generiske og disciplin-specifikke kompetencerammer for data stewardship

Der foregår en international indsats for at professionalisere DS globalt via en nystiftet RDA Interest Group, der sigter på at tackle de udfordringer, der findes i udviklingen af DS professionen.

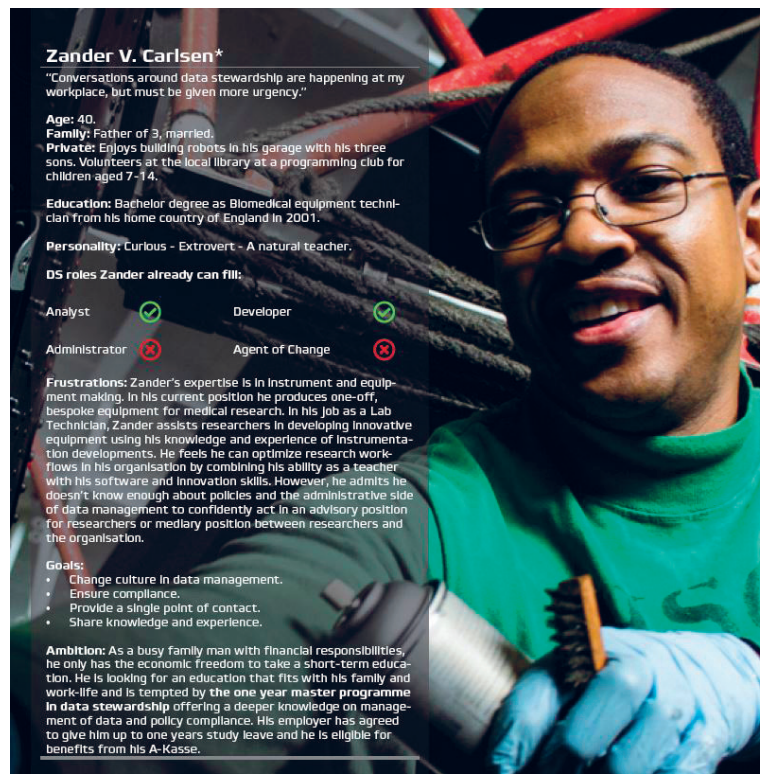
Gruppen, som ikke er godkendt af RDA endnu, forslår en strategi baseret på koordinering og stimulation af projekter der arbejder med professionalisering af DS, curricula, terminologier, karrierespor og træning. RDA er meget synlige på EU-politisk niveau, og i betragtning af bibliotekets professionelle opgave til at være forvaltere (stewards) af information og data, er det vigtigt, at bibliotekarer er med til at udvikle DS profession i nationale og internationale samarbejder, ved at sørge for, at der er muligheder for bibliotekarer til at uddanne sig til dygtige og selvsikre data stewards.

\section{REFERENCER}

Cruz, M et al. (2019, September). Time to Professionalise Data Stewardship.

Zenodo. http://doi.org/10.5281/zenodo.3420179

CODATA, https://codata.org/

Data Steward Education: Coordination or competition? (2019, Oct. 4),

Conference, University of Copenhagen, https://www.deic.dk/da/datamanagement/data-steward-event

DeiC (Danish elnfrastructure Cooperation), https://www.deic.dk/

EDISON - building the data science profession, https://edison-project.eu/

EOSC (European Open Science Cloud), https://www.eosc-portal.eu/

EUA (European University Association), https://eua.eu/

GOFAIR, https://www.go-fair.org/

FAIRsFAIR (EU, H2020), https://www.fairsfair.eu/

RDA (Research Data Alliance), https://rd-alliance.org/

Science Europe, https://www.scienceeurope.org/

Verheul, I et al. (2019, May 6). Data Stewardship on the map: A study of tasks and roles

in Dutch research institutes. Zenodo. http://doi.org/10.5281/zenodo.2669150

Vlachos, E. et al. (2020). Data Files and Documentation - National Coordination of

Data Steward Education in Denmark [Data set]. http://doi.org/10.5081/zenodo.3634756

Wildgaard, L. (2020): Reframing Data Stewardship Education in Denmark and abroad.

Zenodo. http://doi.org/10.5281/zenodo.3628375

Wildgaard, L et al. (2020, January 31). National Coordination of Data Steward Education

in Denmark: Final report to the National Forum for Research Data Management (DM Forum).

Zenodo. http://doi.org/10.5281/zenodo.3609516 